\title{
Effect of Ground Waste Concrete Powder on Cement Properties
}

\author{
Xianwei $\mathrm{Ma}^{1}$ and Zhenyu Wang ${ }^{2}$ \\ ${ }^{1}$ Department of Civil and Material Engineering, Henan University of Urban Construction, Pingdingshan 467036, China \\ ${ }^{2}$ College of Civil Engineering and Architecture, Zhejiang University, Hangzhou 310058, China \\ Correspondence should be addressed to Zhenyu Wang; wzyu@zju.edu.cn
}

Received 20 March 2013; Revised 1 May 2013; Accepted 13 May 2013

Academic Editor: Alex Li

Copyright (C) 2013 X. Ma and Z. Wang. This is an open access article distributed under the Creative Commons Attribution License, which permits unrestricted use, distribution, and reproduction in any medium, provided the original work is properly cited.

\begin{abstract}
The paste/mortar attached to the recycled aggregate decreases the quality of the aggregate and needs to be stripped. The stripped paste/mortar is roughly $20 \%$ to $50 \%$ in waste concrete, but relevant research is very limited. In this paper, the effects of ground waste concrete (GWC) powder, coming from the attached paste/mortar, on water demand for normal consistency, setting time, fluidity, and compressive strength of cement were analyzed. The results show that the $20 \%$ of GWC powder (by the mass of binder) has little effect on the above properties and can prepare C20 concrete; when the sand made by waste red clay brick (WRB) replaces $20 \%$ of river sand, the strength of the concrete is increased by $17 \%$ compared with that without WRB sand.
\end{abstract}

\section{Introduction}

With the rapid development of urbanization, many old buildings have been demolished and a lot of construction waste is generated. In China, construction waste produced from building demolition is estimated to be 400 million tons per year. Landfilling is the most common treatment method, but it leads to the special problem of environment pollution. In addition, the location suitable for landfill is increasingly difficult to find so that the fee of landfill becomes higher. The recycling of construction waste, therefore, is encouraged and supported in many counties.

In China, mostly old buildings of 20 years ago belong to the brick-concrete structure and construction waste includes about $20-30 \%$ waste concrete, $30-40 \%$ red clay brick, and $5 \%-10 \%$ other waste such as glass and ceramic tile. Extensive research has been conducted, but many are related to the recycling use of waste concrete aggregates [1-7]. When waste concrete is crushed, a certain amount of cement paste/mortar is attached to the surface of aggregates. The attached paste/mortar is the main reason for the lower quality of the recycled aggregate compared with the natural aggregate. The concrete with the recycled aggregate generally has inferior strength and durability. Some aggregate refining methods such as "heating and rubbing" [8] and "mechanical grinding" [9] have been developed in order to improve the quality of recycled aggregates by removing the attached paste/mortar. The amount of paste/mortar in waste concrete is about between $20 \%$ and $50 \%$, but relative research is very limited [10-13]. Lv found that when waste concrete powder content is lower than $30 \%$, its effect on cement strength is the same as fly ash's and that its effect becomes more evident after heat treatment [11].

In order to effectively utilize waste concrete, the effects of ground waste concrete (GWC) powder on water demand for normal consistency, setting time, fluidity, and compressive strength of cement were analyzed and the feasibility of C20 concrete prepared with recycled aggregate and GWC powder was also discussed in this paper.

\section{Materials and Methods}

2.1. Materials. The GWC powder was obtained by crushing and grinding the tested OPC concrete specimens in the laboratory. Figure 1 shows the composition of the GWC powder based on XRD analysis. The constituents of the GWC powder are quartz, $\mathrm{Ca}(\mathrm{OH})_{2}$, mullite (from fly ash in cement), tobermorite, and a small amount of unhydrated $\mathrm{C}_{2} \mathrm{~S}$. Tobermorite is formed by the crystallization of C-S-H gel.

PF32.5 grade fly ash cement was adopted and its properties met the requirements of common Portland cement (GB175-2007). 


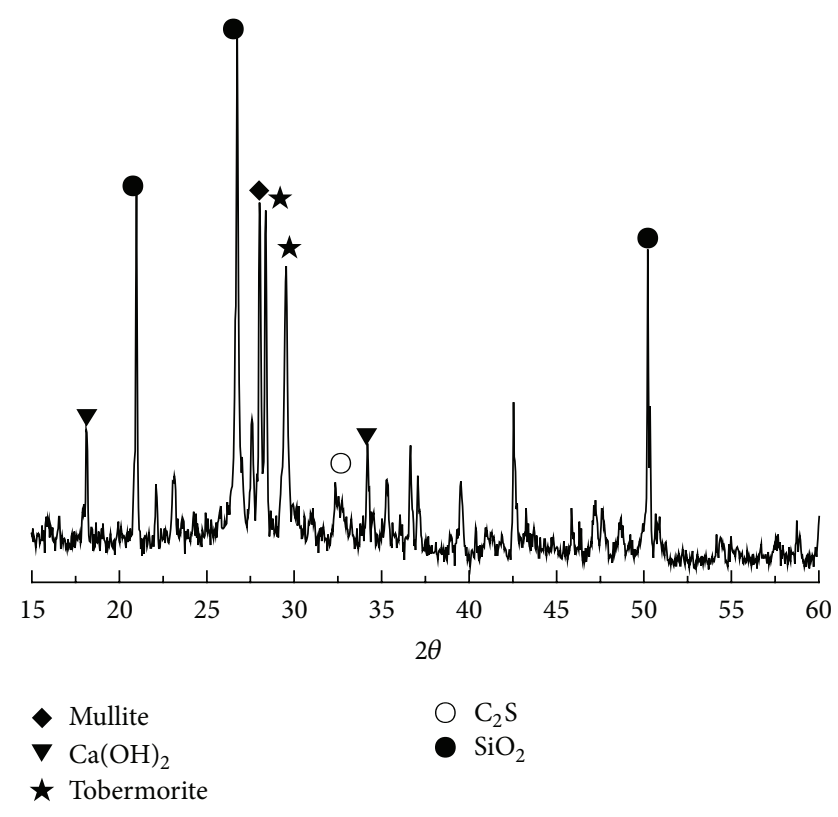

FIGURE 1: XRD pattern of GWC powder.

River sand met the requirements of the sand used in construction (GB/T-14684-2011).

2.2. Experimental Methods. After the 28 days, cured concrete specimens had been tested and left in the air for another 3 months; they were crushed by a jaw crusher and separated into different parts based on particle size. The part passing through the $0.3 \mathrm{~mm}$ sieve was subject to further grinding using a grinding mill so as to ensure that most particles pass through the $0.075 \mathrm{~mm}$ sieve. The obtained GWC powder was mixed with cement at different proportions, $0 \%, 10 \%, 20 \%$, $30 \%$, and $40 \%$ (by the mass of binder). Water demand for normal consistency, setting time, fluidity, and compressive strength of cement were tested according to the requirement of GB175-2007 common Portland cement.

\section{Results and Discussions}

3.1. Water Demand for Normal Consistency and Setting Time of Cement Paste. Table 1 gives water demand for normal consistency (WDNC) and setting time of cement pastes with different amounts of GWC powder. The amount of binding material was $500 \mathrm{~g}$.

With increasing the amount of GWC powder, WDNC is decreased. When the amount of GWC powder is more than $30 \%$, WDNC is evidently reduced. For example, WDNC of a sample with $40 \%$ of GWC powder drops by $9 \%$. The reason is that GWC powders contain a small amount of unhydrated $\mathrm{C}_{2} \mathrm{~S}$ (Figure 1) which slowly reacts with water, and other minerals do not react with water. As a result, WDNC is mainly related to the amount of cement in the GWC-cement system. The reduction of cement's amount in the sample naturally leads to the decrease of WDNC. In addition, Wu et al. analyzed the effect of different fitness of GWC powder on
TABLE 1: WDNC and setting time of cement with different amounts of the GWC powder.

\begin{tabular}{lcccc}
\hline $\begin{array}{l}\text { GWC powder } \\
\text { amount/\% }\end{array}$ & $\begin{array}{c}\text { The depth of } \\
\text { the cone } \\
\text { falling/mm }\end{array}$ & WDNC/g & $\begin{array}{c}\text { Initial } \\
\text { set/min }\end{array}$ & $\begin{array}{c}\text { Final } \\
\text { set/min }\end{array}$ \\
\hline 0 & 28 & 150 & 111 & 228 \\
10 & 27 & 147 & 109 & 232 \\
20 & 28 & 143 & 113 & 237 \\
30 & 29 & 140 & 108 & 233 \\
40 & 28 & 137 & 110 & 230 \\
\hline
\end{tabular}

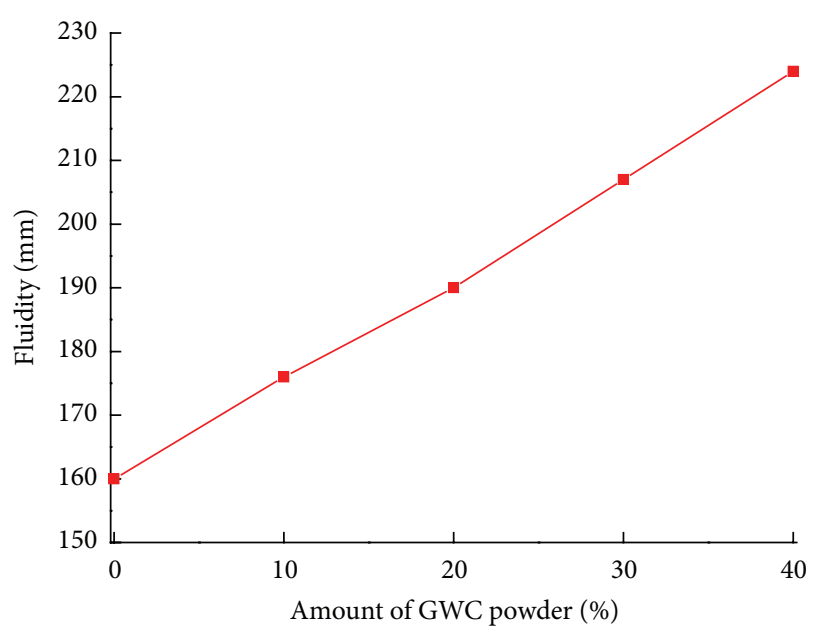

FIGURE 2: Change in fluidity of mortar with GWC powder amount.

WDNC and found that the increase of the fitness has a much lower effect on WDNC [13].

The GWC powder, however, has almost no effect on setting time of cement.

3.2. Fluidity of Cement Mortar. The water/binder ratio of cement mortar remained 0.5. The fluidity of cement mortar with different amounts of GWC powder is shown in Figure 2. The fluidity is almost lineally raised with GWC powder amount rising. For the samples with $40 \%$ of GWC powder, for instance, the fluidity is increased by about $40 \%$.

The change in the fluidity is consistent with that of WDNC, but it does not agree with the results of Lv et al. that the GWC powder decreased the fluidity [11]. Lv et al. thought that the surface of ground particles has some pores which absorb some water. However, the main reason may be the different amount of active particles which react with water and lead to the decrease of free water amount. GWC powder, in our experiment, only contains a very small amount of $\mathrm{C}_{2} \mathrm{~S}$ which has a very slow rate and can be thought not to be active.

3.3. The Strength of Hardened Cement Mortar. Compressive and flexural strengths of hardened cement mortar with different amounts of GWC powder are shown in Figures 3 and 4 . Compressive strengths at 3 and 28 days are reduced with GWC powder amount rising. When the amount of GWC powder is less than $20 \%$, the downward trend of the 


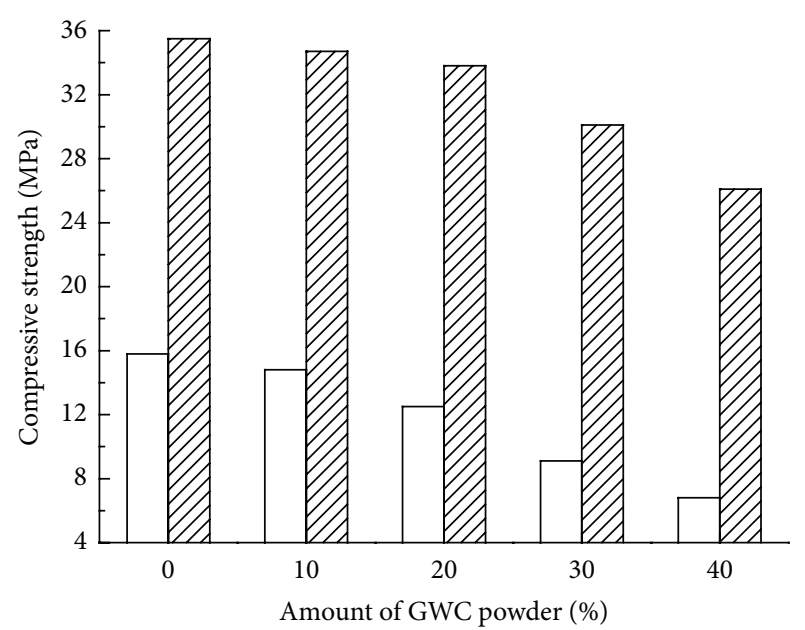

$3 \mathrm{~d}$

V7D 28d

FIGURE 3: Compressive strength of mortar with different amounts of GWC powder.

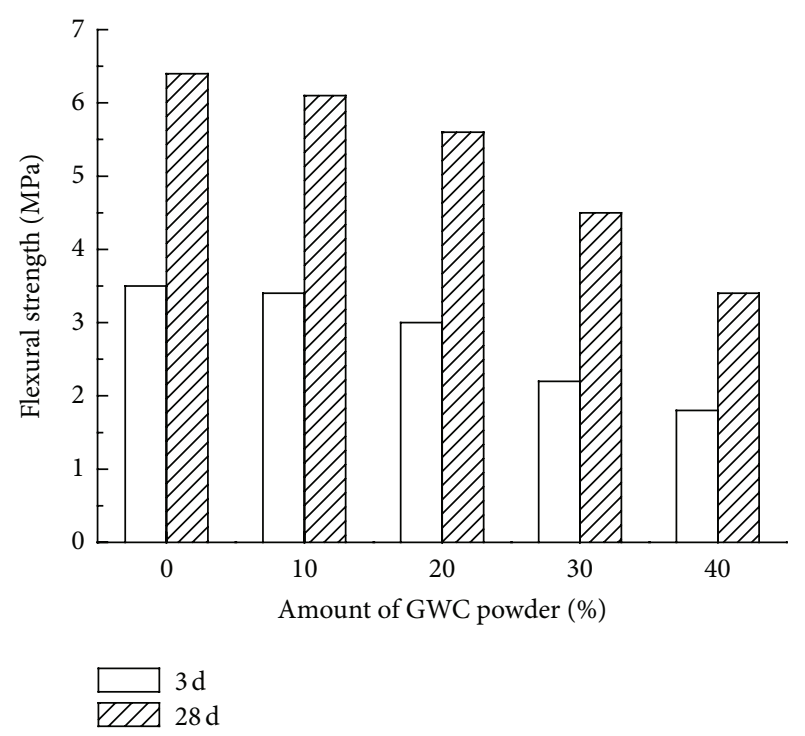

FIGURE 4: Flexural strength of mortar with different amounts of GWC powder.

strength is not very obvious. However, more than $20 \%$ of GWC powder evidently decreases the strength. For example, the strength of the sample with $40 \%$ of GWC powder falls by $57 \%$ at 3 days and by $26 \%$ at 28 days. The change in flexural strength with GWC powder amount is similar to that of compressive strength.

The above results indicate that the inference in Section 3.2 is correct; namely, the hydration activity of the GWC powder is lower. In fact, the building demolished in China was built about 20 years ago and cement in waste concrete had almost been completely hydrated.

For the active excitation of GWC powder, a common method is heat treatment in the range of temperature, such

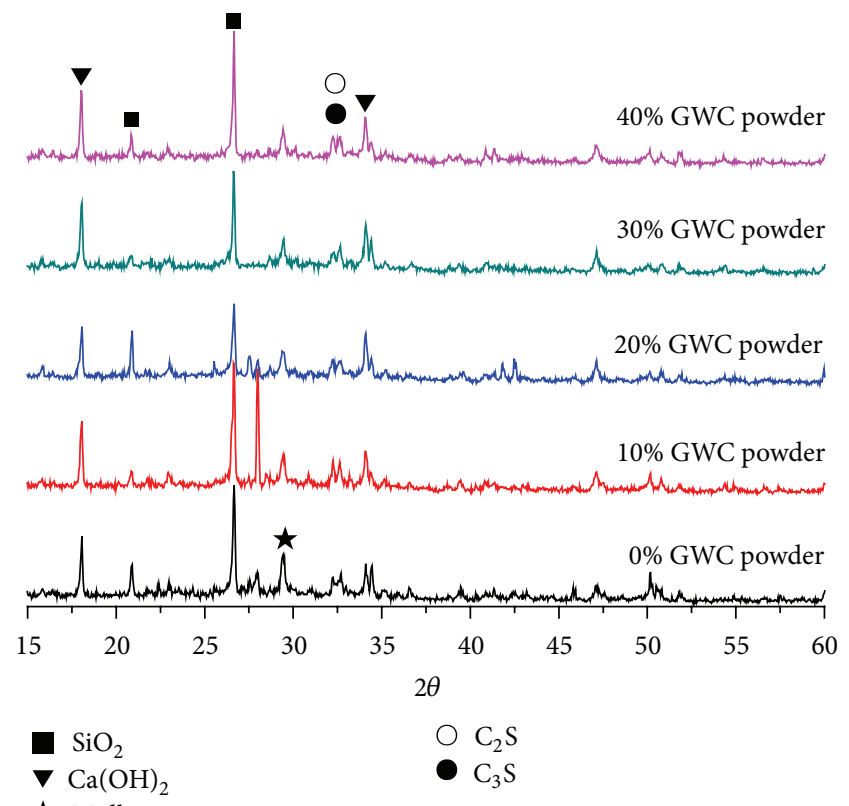

FIGURE 5: XRD pattern of hardened paste.

as $500-800^{\circ} \mathrm{C}$. After heating, some active minerals are formed and improve the strength $[11,12]$. However, the heat treatment for GWC powder is difficult to be realized in the ordinary building material companies. The active effect of GWC powder, therefore, is not to be further researched in this paper.

It needs to be noticed that the $20 \%$ of GWC powder has little effects on compressive strength (falling only $1.5 \mathrm{MPa}$ ) and would bring considerable economic benefit. The following design relating to the recycled concrete is based on the $20 \%$ of replacement.

3.4. Constituents and Structures of Hardened Paste. An XRD pattern of hardened paste with the GWC powder at 28 days is shown in Figure 5. The major constituents of the hardened paste are $\mathrm{SiO}_{2}, \mathrm{Ca}(\mathrm{OH})_{2}$, mullite, $\mathrm{C}-\mathrm{S}-\mathrm{H}$, and a small amount of unhydrated $\mathrm{C}_{2} \mathrm{~S}$ and $\mathrm{C}_{3} \mathrm{~S}$. $\mathrm{SiO}_{2}$ is provided by the GWC powder. The intensities of unhydrated $\mathrm{C}_{2} \mathrm{~S}$ and $\mathrm{C}_{3} \mathrm{~S}$ (about $32.5^{\circ}$ ) in all the samples are almost the same but the intensities of the $\mathrm{SiO}_{2}$ peak (about $26^{\circ}$ ) do not change with the amount of the GWC powder. The results indicate that the amount of each mineral in the GWC powder is very unsteady, but the selecting and treating procedures of sample are very different to control. Luckily, the amount of unhydrated cement in the GWC powder is very low and has little contribution to the cementitiousness of hardened paste so that the change of strength caused by the amount of the GWC powder still shows a relatively reasonable trend.

The morphology of hardened paste with the GWC powder at 3 and 28 days is shown in Figure 6. Amorphous C-S-H gel, needle-like Aft, and blocky $\mathrm{Ca}(\mathrm{OH})_{2}$ are easily found in the 3 days' samples. The main difference is that, at 3 days, the structure of the sample with the GWC powder is looser than 


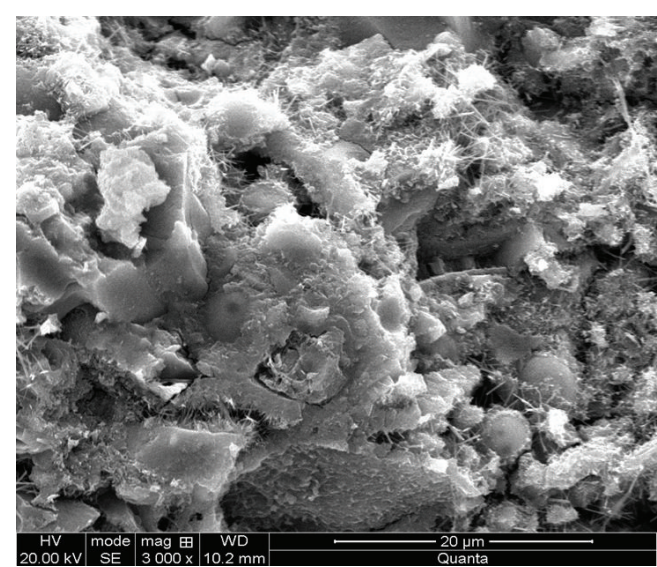

(a) Without GWC powder, 3 days

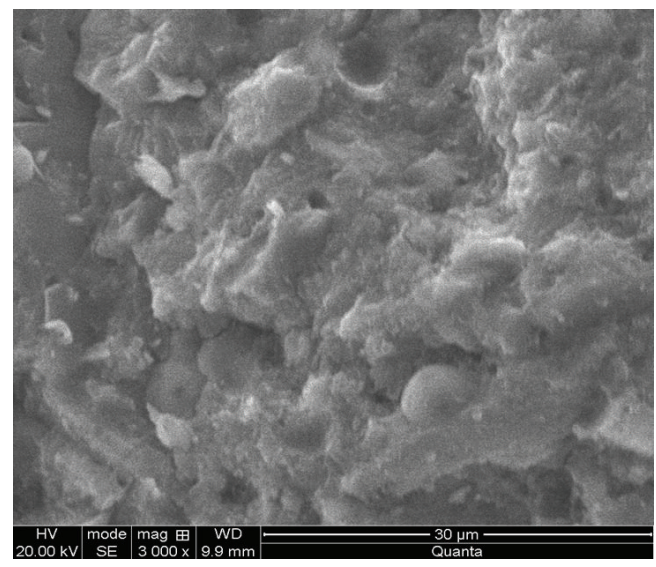

(c) Without GWC powder, 28 days

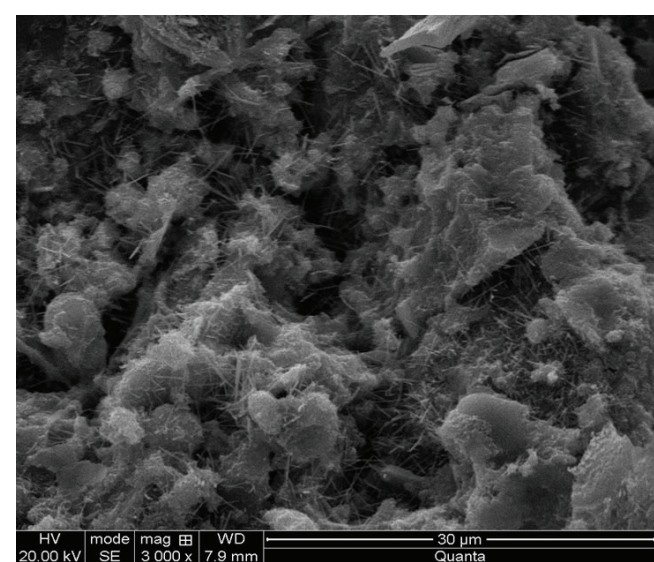

(b) With $20 \%$ GWC powder, 3 days

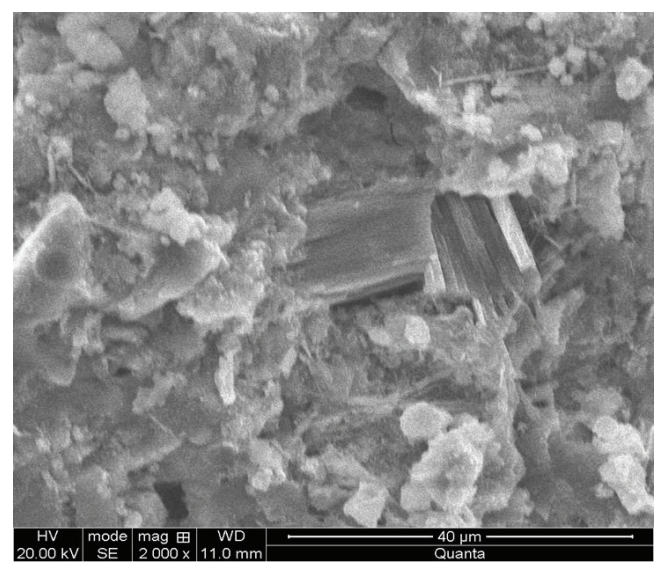

(d) With $20 \%$ GWC powder, 28 days

FIGURE 6: Morphology of hardened paste.

that without the GWC powder, but the difference becomes unobvious at 28 days. The results indicate that the 28 days' strength should not vary much in both samples (actually $1.5 \mathrm{MPa})$.

3.5. C20 Recycling Concrete Design. The replacement of 32.5 grade fly ash cement by the GWC powder was $20 \%$. Recycled aggregate came from waste concrete in the laboratory. Recycled sand made by waste red clay bricks (WRB) was used to replace river sand, and $\mathrm{WRB}$ sand had the same particle size distribution and fineness module as river sand. The ratio of cement, stone, sand, and water was $1: 1.95: 3.05: 0.56$.

Table 2 gives compressive strength and slump of concrete with WRB sand. Without WRB sand, the strength has reached $23.6 \mathrm{MPa}$ at 28 days. When WRB sand is added, the slump is reduced but the strength is increased. For example, when WRB sand replaces $20 \%$ of river sand, the strength is increased by $17 \%$ compared with that without WRB sand. The results may be related to the porous structure of WRC sand which absorbs some water in mixing and releases the water during the hardening. The released water will promote the hydration of cement. Wang and Xiao et al. also found the reinforcement of WBC as aggregate $[14,15]$.

The aforementioned results indicate that WRB sand is a very promising concrete additive and should be further
TABLE 2: Compressive strength and slump of concrete with WRB sand.

\begin{tabular}{|c|c|c|c|}
\hline \multirow{2}{*}{ SRCB amount/\% } & \multicolumn{2}{|c|}{ Compressive strength/MPa } & \multirow{2}{*}{ Slump $/ \mathrm{mm}$} \\
\hline & $3 \mathrm{~d}$ & $28 \mathrm{~d}$ & \\
\hline $0 \%$ & 7.5 & 23.6 & 45 \\
\hline $10 \%$ & 7.8 & 25.8 & 40 \\
\hline $20 \%$ & 9.0 & 27.7 & 30 \\
\hline
\end{tabular}

researched. Relevant research would be of considerable benefit and promote the effective utilization of construction waste.

\section{Conclusions}

(1) The GWC powder decreases water demand for normal consistency (WDNC) of cement paste, especially when the amount of the GWC powder is more than $30 \%$, but it has almost no effect on setting time.

(2) When the water/binder of cement mortar is 0.5 , the fluidity is almost lineally raised with GWC powder amount.

(3) When the amount of the GWC powder is less than $20 \%$, the downward trend of the strength is not very 
obvious. More than 20\% GWC powder, however, evidently decreases the strength.

(4) Compressive strength of concrete with 20\% GWC powder and recycled aggregate reaches $23.6 \mathrm{MPa}$ at 28 days. When WRB sand replaces $20 \%$ of river sand, the strength is increased by $17 \%$ compared with that without WRB sand.

\section{Acknowledgment}

This work is supported by the Research Foundation of Henan University of Urban Construction (no. 2012JZD001).

\section{References}

[1] T. C. Hansen, Recycling of Demolished Concrete and Masonry, Taylor and Francis, Oxford, UK, 1992.

[2] M. Tavakoli and P. Soroushian, "Strengths of recycled aggregate concrete made using field-demolished concrete as aggregate," ACI Materials Journal, vol. 93, no. 2, pp. 182-190, 1996.

[3] K. K. Sagoe-Crentsil, T. Brown, and A. H. Taylor, "Performance of concrete made with commercially produced coarse recycled concrete aggregate," Cement and Concrete Research, vol. 31, no. 5, pp. 707-712, 2001.

[4] A. Shayan and A. Xu, "Performance and properties of structural concrete made with recycled concrete aggregate," ACI Materials Journal, vol. 100, no. 5, pp. 371-380, 2003.

[5] V. W. Y. Tam, X. F. Gao, and C. M. Tam, "Microstructural analysis of recycled aggregate concrete produced from two-stage mixing approach," Cement and Concrete Research, vol. 35, no. 6, pp. 1195-1203, 2005.

[6] J. Z. Xiao, J. B. Li, and C. Zhang, "On relationships between the mechanical properties of recycled aggregate concrete: an overview," Material Structure, vol. 39, pp. 655-364, 2006.

[7] M. Malešev, V. Radonjanin, and S. Marinković, "Recycled concrete as aggregate for structural concrete production," Sustainability, vol. 2, pp. 1204-1225, 2010.

[8] C. Thomas, J. Setién, J. A. Polanco, P. Alaejos, and M. Sánchez de Juan, "Durability of recycled aggregate concrete," Construction and Building Materials, vol. 40, pp. 1054-1065, 2013.

[9] K. Yasuhiro, H. Hiroshi, U. Noboru, N. Yoko, Y. Nobuyuki, and M. Yoshiaki, "A closed-loop concrete system on a construction site," Technical Research Report of Shimizu Corporation, vol. 79, pp. 1-10, 2004.

[10] Y. Kunio, I. Kazumasa, S. Shigeki, and T. Daijiro, "A study of cyclic use of aggregate for structural concrete," Takenaka Technical Research Report, no. 62, pp. 5-16, 2006.

[11] X. Y. Lv, L. S. Wang, X. Chen, and Q. Y. Li, "Experimental study on the activity of concrete recycled powder," Journal of Qingdao Technological University, vol. 30, pp. 137-139, 2009.

[12] S. G. Hu and Y. J. He, "Preparation of regenerated binding materials using waste concrete," Journal of the Chinese Ceramic Society, vol. 35, pp. 593-598, 2007.

[13] X. M. Wu, J. J. Yang, and M. Huang, "Construction waste ground powder as mineral admixtures on the influence of the physical and mechanical properties of cement," New Building Materials, no. 4, pp. 16-17, 2004.

[14] W. X. Wang, "Performance of concrete with renewable waste brick aggregate modified by fly ash," Building Block and Block Construction, no. 1, pp. 12-14, 2007.
[15] B. Xiao, Z. Z. Liu, X. L. Li et al., "Experimental study on recycling waste bricks as aggregates," Journal of Taizhou University, vol. 32, no. 6, pp. 51-55, 2010. 

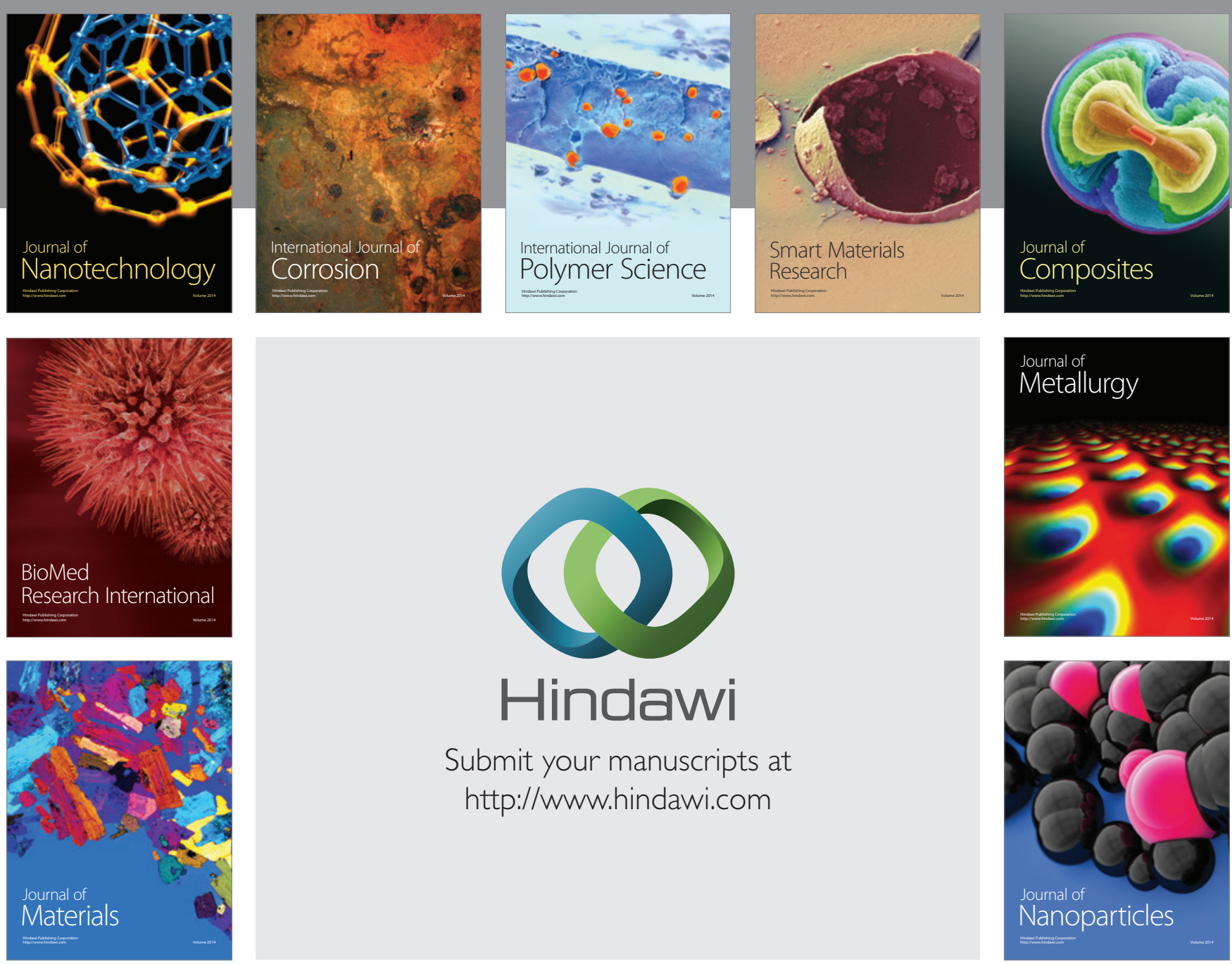

Submit your manuscripts at http://www.hindawi.com
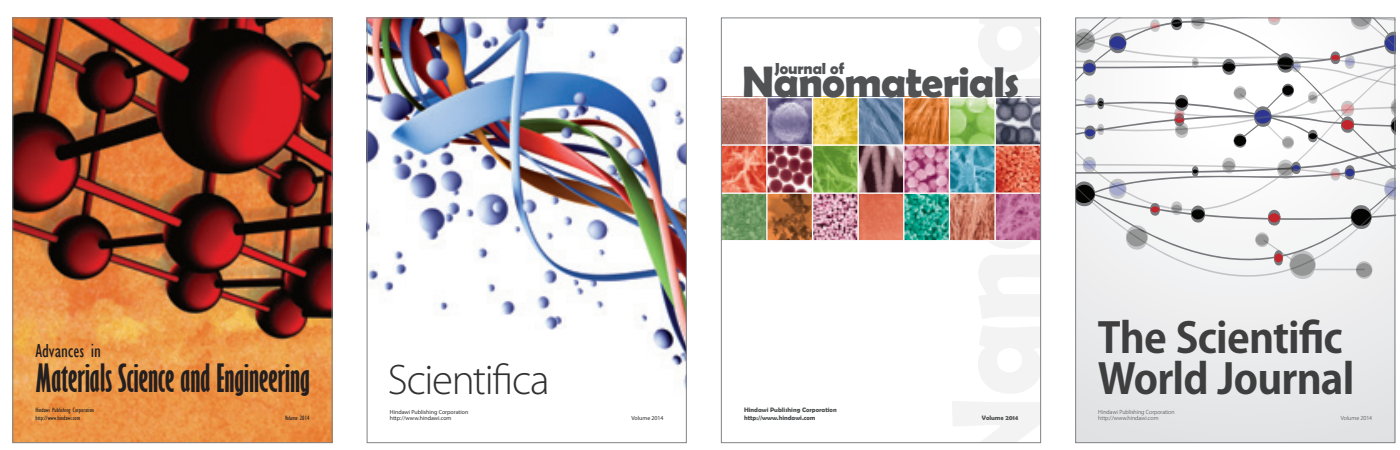

\section{The Scientific World Journal}
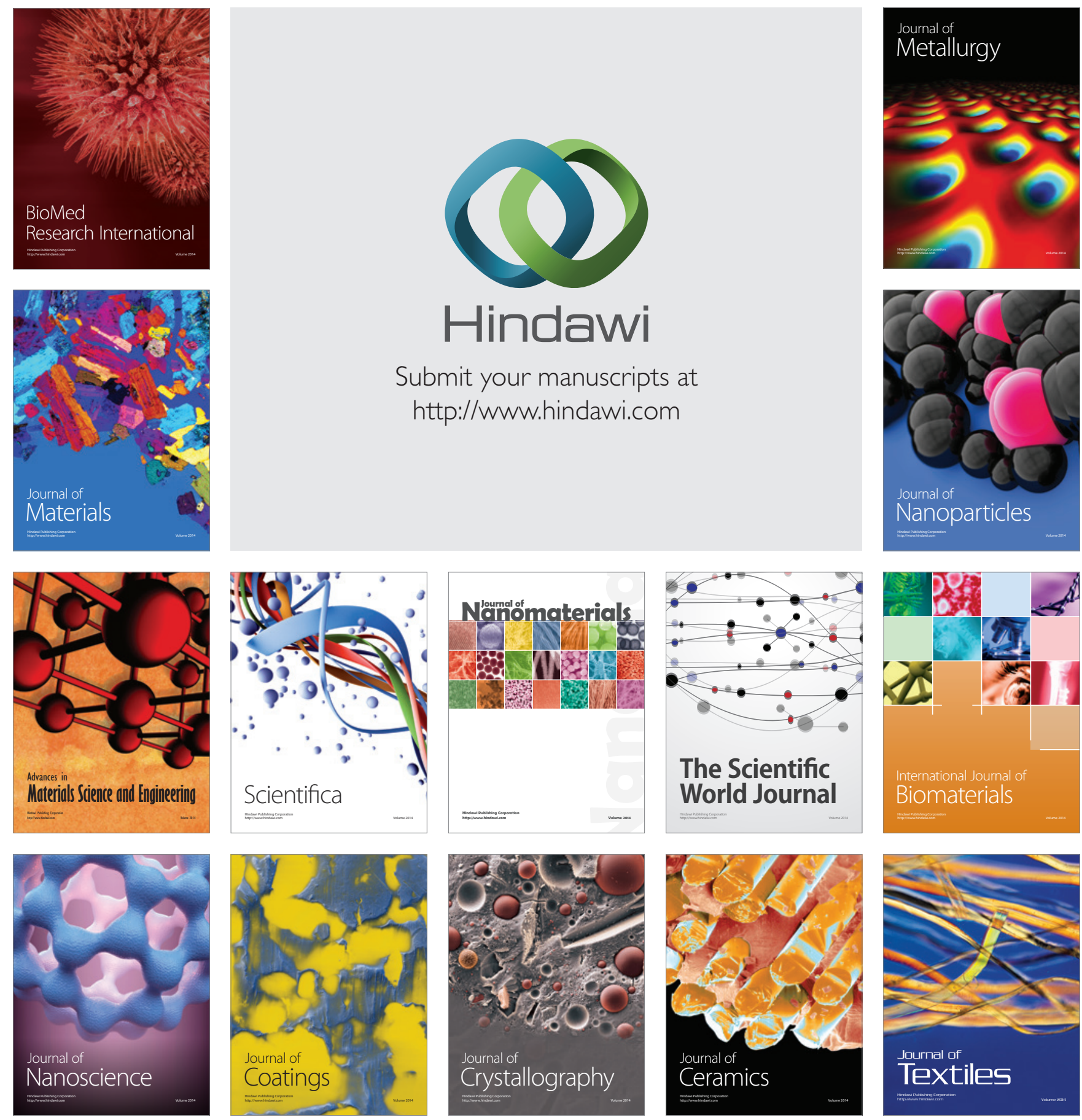